\title{
TESTING OF OVERSULFATED CEMENT BASED ON NATURAL POUZZOLANE
}

\author{
Dimbimalala Mavoniaina \\ RATSARAHASINA ${ }^{1}$ \\ ${ }^{1}$ Researcher,
}

Materials and Civil Engineering Department,

National Center of Industrial and Technology

Researches

\author{
Hery Mikaela \\ RATSIMBAZAFY ${ }^{2}$ \\ ${ }^{2}$ Doctor, \\ Materials and Civil Engineering Department, \\ National Center of Industrial and Technology \\ Researches
}

\author{
Jean de Dieu RAMAROSON ${ }^{3}$ \\ ${ }^{3}$ Professor, \\ Materials and Civil Engineering Department, \\ National Center of Industrial and Technology Researches
}

Article DOI: https://doi.org/10.36713/epra6394

\begin{abstract}
Currently, cement plants face a major environmental problem due to greenhouse gas emissions during the production of Portland clinker. In order to mitigate this negative impact on the environment, this study aims to partially or completely replace conventional cement with a new type of cement that has properties similar to conventional cements. To enhance local mineral resources, the use of natural pouzzolane is adopted. As this binder is obtained by a mixture of activated natural pouzzolane, gypsum, lime and a small amount of conventional cement, the work is to determine the optimal parameters to obtain the best result, and the value for money. The property of the natural pouzzolane needs to be improved by thermal activation to obtain better activity, a treatment of 2 hours at $5000 \mathrm{C}$ was carried out. Then several tests were carried out by varying the different parameters that can influence the characteristics of the cement developed. The best composition determined is $65 \%$ pouzzolane, $15 \%$ cement, and $5 \%$ gypsum. A comparative study was carried out to classify this new type of cement. From a mechanical performance point of view, this oversulphate cement is able in the medium term to compete with the conventional cements produced by the company HOLCIM, and even outperform it in the longer term. In addition, the cost of production and the selling price are lower than those of conventional cements. So the use of this cement in the field of civil engineering can be considered, it has potential and contributes to the reduction of greenhouse gas emissions. Even if the results are sufficient, a thorough study is still needed to improve this type of cement.
\end{abstract}

KEYWORDS: pouzzolane, clinker, oversulfated cement

\section{1- INTRODUCTION}

Currently, the world is facing a major problem because of climate change: the global temperature is rising, the precipitation is decreasing and this is leading to a decrease in farmers' agricultural income. A $1 \%$ increase in temperatures leads to a $3.6 \%$ drop in farm incomes [1].

One of the main causes of this change is the massive production of greenhouse gases. It is heavy industries such as the cement industry that emit the most emissions. The production of one tonne of cement causes the release of one tonne of $\mathrm{CO}_{2}, 55 \%$ of emissions come from the decarbonization process and $45 \%$ from combustion [2].

Despite the harmful consequences of cement production, the development of infrastructure and habitats cannot do without its use.

Research is currently being carried out to solve this problem as well as the search for other types of cement or the most commonly used conventional cement substitute binders. 
Research is mainly focused on the development of new cement substitute materials.

Supersulfated cement is part of this alternative cement. Supersulphated cement is a cement whose main composition is blast furnace slag.

For the particular case of Madagascar, it does not have steel industries that can produce blast furnace slag, yet it possesses other raw materials that are abundant and can be used for the manufacture of such cement. This inspired us to research the development of oversulfated cement based on natural pouzzolane.

Research has already been carried out on the use of natural pouzzolanes to make road hydraulic binder.

In this work, they sought to valorize a paper mill fly ash, an industrial by-product from paper recycling, and a natural pouzzolane as the main components of new road hydraulic binder.

Extensive physical, chemical and mineralogical characterizations of these materials were carried out, and their reactivity to lime and gypsum was evaluated using a new chemical quantification method developed to assist in the formulation of road hydraulic binder.
This method, which has yet to be optimized, has nevertheless made it possible to extract formulations of road hydraulic binder from the pouzzolane or the flying stationery ash without clinker [3].

In our case, the objective of this work is to obtain a new type of cement that can compete with local cements by valuing local natural resources and combating climate change.

Our job is to see if natural pouzzolane can replace the blast furnace slag, which is conventionally used in the manufacture of oversulfated cement.

We will also check whether the production of this type of cement reduces the emission of greenhouse gases and whether the price of the resulting cement is cheaper compared to that of conventional cement.

\section{2- METHODOLOGY} 2.1- Materials

The materials used in this work are

- Ball shredder: capacity: 151, Power 1400w, $220 \mathrm{~V}$

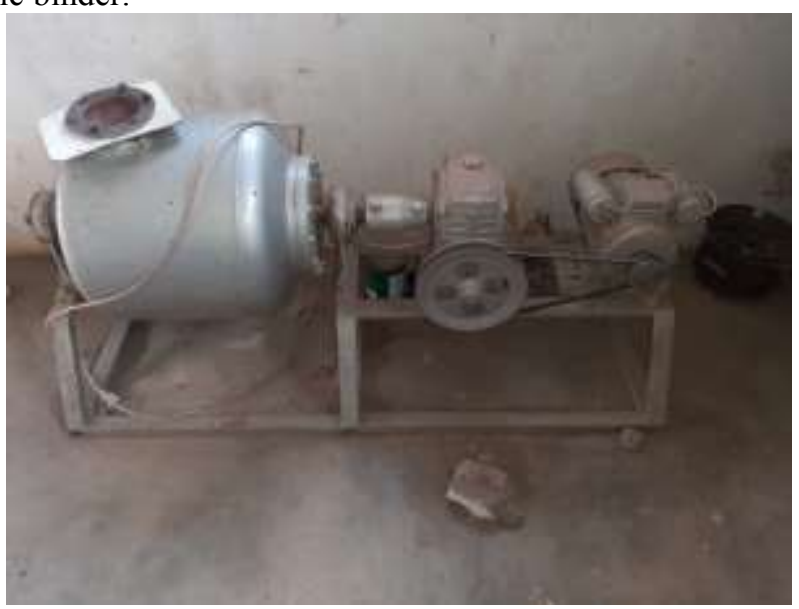

Fig 1: Ball shredder

- four : Maximum temperature: $1100 \circ \mathrm{oC}$

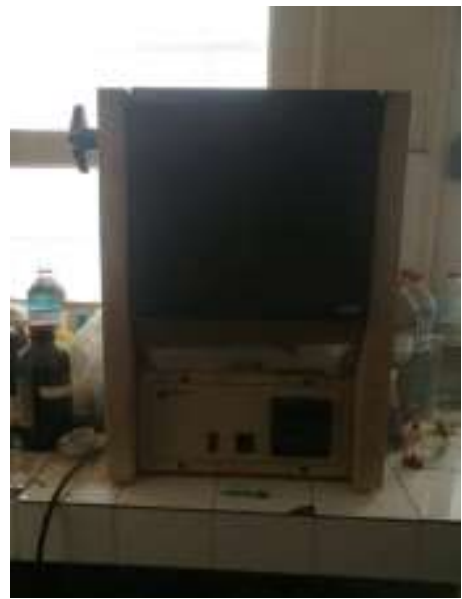

Fig 2: Four: OS1 Carbolite R, Phase 1, GEM Type 11/ 3

- $\quad$ Press 


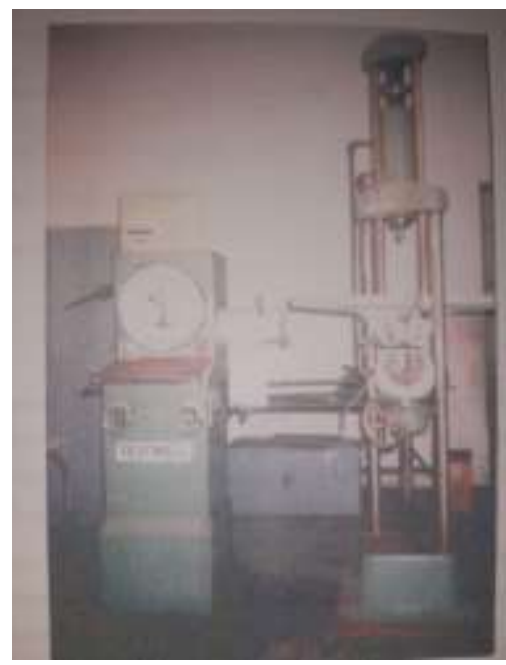

Fig 3 : TESTWELL

The study was carried out at the CNRIT Research Laboratory, Ankatso Technical Block, National Public Works Laboratory and building(LNTPB), and Mining Laboratory

\section{2- Methods}

To verify that oversulfated cement made from natural pouzzolane can replace conventional cement, we will adopt the following methods:

Step 1: preparation of natural pouzzolane;

2iem steps: testing of oversulfated cement production;

3iem steps: comparative studies.

\subsection{1- Preparation of natural pouzzolane}

As a raw material, we used natural pouzzolane from Ivohitra.

Ivohitra is located in the rural commune of Antsirabe. The term pouzzolane refers to all natural and artificial materials rich in silica and alumina capable of reacting at room temperature with lime.

The natural pouzzolane is nothing but volcanic projections.

Before any test, the natural pouzzolane must be characterized and prepared, the main objective of this operation is to know the activity of the natural pouzzolane and to correct its characteristics if necessary.

The preparation steps are:

- Grinding the pouzzolane

- Characterization of the pouzzolane

- Activation of natural pouzzolane

\subsubsection{1- Grinding of the pouzzolane}

The grinding was carried out at the Materials and Civil Engineering Laboratory of the CNRIT
The pouzzolane was ground and sifted until a powder of less than 80 degrees, a diameter used for mineral additives, was obtained.

\subsubsection{2- Characterization of natural pouzzolane} Chemical analyses were carried out to determine the chemical characteristics of natural pouzzolane The chemical characteristics we are interested in are the content of silica, alumina, iron oxide and especially the lime content.

\subsubsection{3- Activation of natural pouzzolane}

This is the most important step in the preparation of natural pouzzolane. To activate the pouzzolane, the thermal activation method was chosen.

The pouzzolane is brought to different temperatures The temperature is then maintained for 1 hour.

The purpose of activation is to make a crystallized material amorphous. In this state, it is able to combine more easily with lime by presenting hydraulic properties by formation of aluminates and silicates.

The tests were carried out with the temperatures: $\mathrm{O}^{\circ} \mathrm{C}, 500^{\circ} \mathrm{C}, 600^{\circ} \mathrm{C}$ and $700^{\circ} \mathrm{C}$

Two methods have been adopted:

$1^{\text {st }}$ method : only the pouzzolane that is brought to different temperatures

$2^{\text {nd }}$ method : the pouzzolane is mixed with lime before cooking.

\section{3- Production tests}

The stage of the manufacture of oversulfated cement based on natural pouzzolane

\subsection{1- Determining the different} optimal manufacturing parameters 
Several tests have been carried out to determine the optimum mixture of oversulfated cement. The method adopted here is to gradually replace the amount of cement with the activated natural pouzzolane starting with the mixture $90 \%$ pouzzolane and $10 \%$ cement. Here one or two parameters have been varied, the others are set by doing tests of the formulation of the test tubes.

In this study, to improve the characteristics of the resulting cement, gypsum and lime are also used as additives and we also varied their content at the same time as that of cement or pouzzolane.

The gypsums used were taken from Ambondromamy's quarry.

Cement is the Manda cement produced by Holcim. It is an artificial portland cement whose resistance class CEM 42.5.

Lime is the one produced by Chaumad.

\subsection{2- Characterization of the resulting product}

Mechanical tests were conducted to determine compression resistance and traction resistance of the product.
We made test tubes on normal pasta. After a set period of time and under specific conservation conditions, the mechanical characteristics of the test tube are tested on a test-Well press, which is a resistance measuring device.

\section{4- Comparative studies}

A comparative study is needed to compare the characteristics of the resulting cement compared to other conventional cements. We compared mainly the mechanical characteristics, the impacts of its production on the environment and the price.

\section{3- RESULTS AND DISCUSSIONS} 3.1- Results

It should be noted that all of the values cited in this paragraph are the average of the 3 samples for each test conducted. The tests were carried out on pure pate moulded in the form of a cylindrical test tube, and only compression resistance is taken into account.

\subsection{1- Chemical characteristics of the pouzzolane}

Table 1: Chemical Characteristics of Natural Pouzzolane

\begin{tabular}{|c|c|c|c|c|}
\hline Oxides & $\mathbf{S i O}_{2}$ & $\mathbf{F e}_{2} \mathbf{O}_{3}$ & $\mathbf{A l}_{\mathbf{2}} \mathbf{O}_{3}$ & $\mathbf{C a O}$ \\
\hline \% mass & 48.8 & 18.9 & 9.7 & trace \\
\hline
\end{tabular}

We found that the lime content is very low.

\subsection{2- Justification of activation}

To verify the activity of the pouzzolane, the mechanical characteristics of the pouzzolane-cement mixture must be determined

Mix composition: $90 \%$ Pouzzolane , 10\% cement

Table 2: Resistance to compression of mixture natural pouzzolane - cement without activation over time

\begin{tabular}{|c|c|c|c|c|c|}
\hline Ages (days) & 7 & 14 & 28 & 64 & 90 \\
\hline Rc (MPa) & - & 0.6 & 1.7 & 2 & 2.5 \\
\hline
\end{tabular}

The compression resistance found from this table is weak, this means that the pouzzolane is not very active and this justifies the need to activate the pouzzolane before its use.

\subsection{3- Activation of the pouzzolane} The purpose of this step is to determine the optimal conditions and parameters that will achieve the maximum pouzzolanic activity of the natural pouzzolane.

Mix composition: 65\% Pouzzolane - 15\% Gypsum 5\% Cement - 15\% Lime

Temperature change: $0^{\circ} \mathrm{C}, 500^{\circ} \mathrm{C}, 600^{\circ} \mathrm{C}, 700^{\circ} \mathrm{C}$ $1^{\text {st }}$ method: thermal activation of the pouzzolane only 


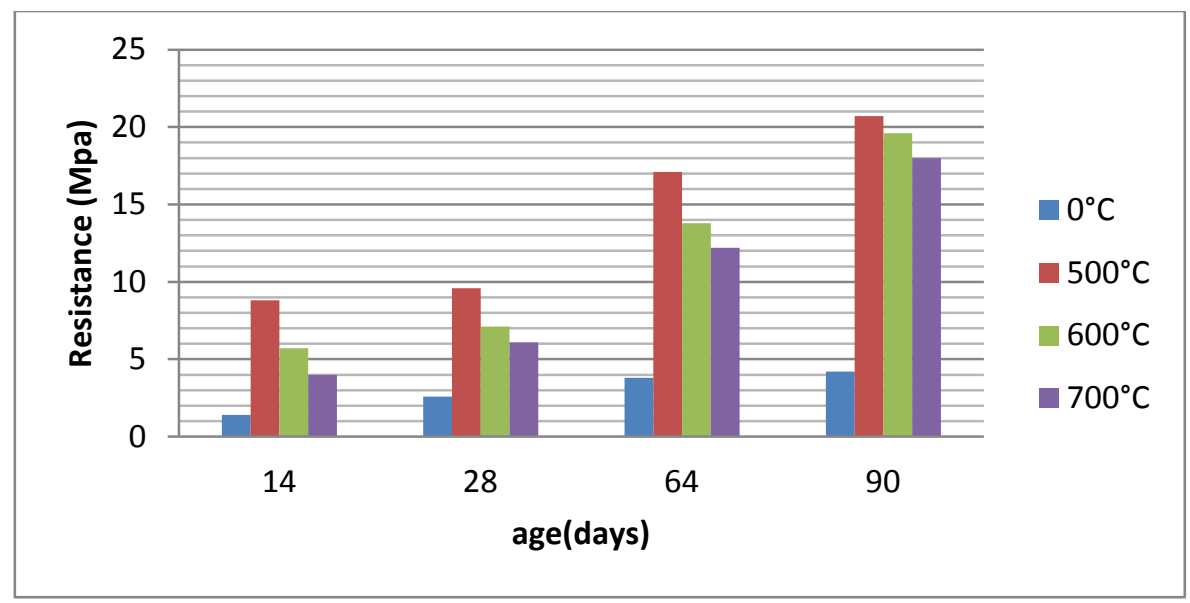

Fig 4 : result with thermally activated pouzzolane only according to temperature:

The histogram shows that the resistance to compression of the resulting product is satisfactory from $500^{\circ} \mathrm{C}$. It can be seen that after $500{ }^{\circ} \mathrm{C}$ the rise in temperature no longer has a large influence on compression resistance, and it has even been seen to decrease. During thermal activation, the color of the pouzzolane varies from black to brown and even brick red if the temperature continues to rise. So the increase in temperature leads to an increase in iron oxidation by turning ferrous oxide into iron oxide. $2^{\text {nd }}$ method: Thermal activation of the pouzzolanelime mixture

Composition used: 65\% Pouzzolane - 15\% Gypsum 5\% Cement - 15\% Lime

Temperature change: $0^{\circ} \mathrm{C}, 500^{\circ} \mathrm{C}, 600^{\circ} \mathrm{C}, 700^{\circ} \mathrm{C}$

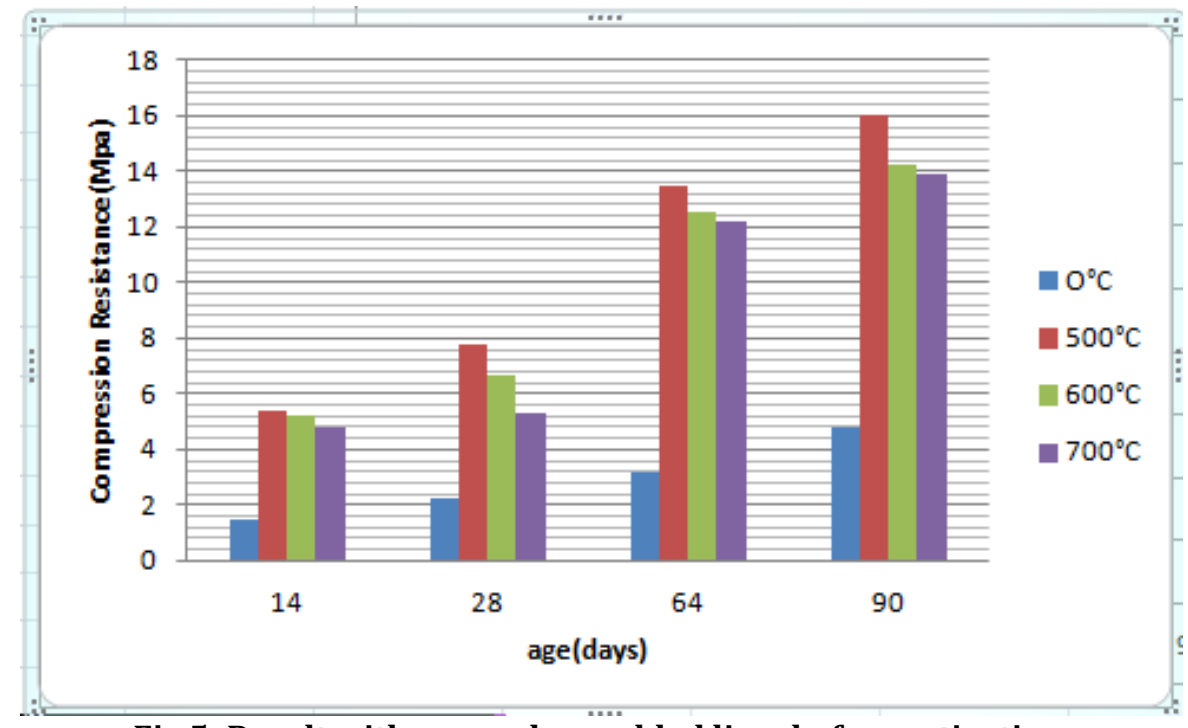

Fig 5: Result with pouzzolane added lime before activation

The result shows that even if lime is mixed with the pouzzolane before activation, the activation temperature remains at $500^{\circ} \mathrm{C}$.

For this second method, it has drawbacks. During the preparation of the test tubes, there is an increase in the demand for water during the waste, and the reaction is followed by a strong release of heat. We found that the first method gave the best resistance to compression.
For the rest of our investigations, the temperature of $500^{\circ} \mathrm{C}$ is then adopted as the activation temperature of the pouzzolane, and only the pouzzolane is activated before mixing.

\section{2- Development of cement based on natural pouzzolane}

Research focuses on the influence of different parameters on the resistance to compression of the cement developed 
The parameters studied are: the content of Pouzzolane, lime, and gypsum, as well as the mode of preservation of the test tubes.

Determining compression resistance is always the factor that determines the quality of the cement obtained.

\subsection{1- Influence of simultaneous addition of lime and gypsum on prepared cement}

Here we take the mixture $90 \%$ Pouzzolane and $10 \%$ cement as the base (mix of pouzzolanic cement). The cement content is set at $10 \%$, the other grades are varied, respecting the entire mixture at $100 \%$.

Table 3: Influence of simultaneous presence of gypsum and lime

\begin{tabular}{|c|c|c|c|c|c|c|c|c|}
\hline \multirow{2}{*}{ test } & \multicolumn{4}{|c|}{ Composition(\%) } & \multicolumn{5}{c|}{ Rc (Mpa) } \\
\cline { 2 - 9 } & $\mathrm{P}$ & $\mathrm{G}$ & $\mathrm{L}$ & $\mathrm{C}$ & $14 \mathrm{~J}$ & $28 \mathrm{~J}$ & $64 \mathrm{~J}$ & $90 \mathrm{~J}$ \\
\hline E1 & 90 & 0 & 0 & 10 & 0.6 & 1.7 & 2 & 3 \\
\hline E2 & 80 & 10 & 0 & 10 & 1.4 & 2.1 & 4.3 & 6.3 \\
\hline E3 & 70 & 0 & 20 & 10 & 2.4 & 3.8 & 5.1 & 7.5 \\
\hline E4 & 60 & 10 & 20 & 10 & 7.4 & 16.9 & 24.6 & 27.2 \\
\hline E5 & 60 & 0 & 0 & 40 & 7.2 & 14.8 & 23.7 & 25.6 \\
\hline
\end{tabular}

According to the results of Table 3, the E4 test yielded the best result, the mechanical resistance is the highest. The simultaneous presence of gypsum and lime improves compression resistance.

\subsection{2- Influence of lime content}

Here, the cement and gypsum levels are set at $10 \%$, and the others are varied, always respecting the totality equal to $100 \%$

Table 4: Influence of Lime Content on Compression Resistance

\begin{tabular}{|c|c|c|c|c|c|c|c|c|}
\hline \multirow{2}{*}{ test } & \multicolumn{4}{|c|}{ Composition(\%) } & \multicolumn{4}{c|}{ Rc (Mpa) } \\
\cline { 2 - 9 } & $\mathrm{P}$ & $\mathrm{G}$ & $\mathrm{C}$ & $\mathrm{L}$ & $14 \mathrm{~J}$ & $28 \mathrm{~J}$ & $64 \mathrm{~J}$ & $90 \mathrm{~J}$ \\
\hline E2 & 80 & 10 & 10 & 0 & 1.4 & 2.1 & 4.3 & 5.7 \\
\hline E6 & 75 & 10 & 10 & 5 & 3.4 & 10.2 & 18.5 & 23.8 \\
\hline E 7 & 70 & 10 & 10 & 10 & 9.1 & 15.3 & 22.4 & 27.6 \\
\hline E8 & 65 & 10 & 10 & 15 & 10.2 & 19.8 & 26.9 & 33.8 \\
\hline E4 & 60 & 10 & 10 & 20 & 7.4 & 16.9 & 24.6 & 30.4 \\
\hline E9 & 55 & 10 & 10 & 25 & 7.2 & 16.2 & 23.8 & 30.2 \\
\hline
\end{tabular}

The table shows that the E8 test gave the best mechanical resistance.
3.2.3 - Influence of cement content

Referring to the previous results, we kept the $\mathrm{P}=65 \%$ pouzzolane content and the lime content $\mathrm{CH}-15 \%$

Table 5: Influence of Cement Content

\begin{tabular}{|c|c|c|c|c|c|c|c|c|}
\hline test & \multicolumn{4}{|c|}{ Composition(\%) } & \multicolumn{4}{c|}{ Rc (Mpa) } \\
\hline & $\mathrm{P}$ & $\mathrm{G}$ & $\mathrm{C}$ & $\mathrm{L}$ & $14 \mathrm{~J}$ & $28 \mathrm{~J}$ & $64 \mathrm{~J}$ & $90 \mathrm{~J}$ \\
\hline E10 & 65 & 20 & 0 & 15 & 1.5 & 2.6 & 3.8 & 5.0 \\
\hline E11 & 65 & 15 & 5 & 15 & 8.8 & 9.6 & 17.1 & 20.5 \\
\hline E8 & 65 & 10 & 10 & 15 & 10.2 & 19.8 & 26.9 & 31.2 \\
\hline E12 & 65 & 5 & 15 & 15 & 11 & 20.1 & 27.2 & 37.1 \\
\hline E13 & 65 & 0 & 20 & 15 & 6.7 & 12.4 & 21.5 & 26.3 \\
\hline
\end{tabular}

In all the results obtained, the E12 test produced the best result, the composition of which is: $65 \%$ of pouzzolane $-5 \%$ of gypsum $-15 \%$ of cement $-15 \%$ of lime.

3.2.4- Influence of the way in which conservation is made Table 6: Conservation Influence

\begin{tabular}{|c|c|c|}
\hline \multirow{2}{*}{$\mathrm{R}_{\mathrm{C}}$ (Mpa) } & \multicolumn{2}{|c|}{ How to preserve } \\
\cline { 2 - 3 } & In the water & In the air \\
\hline Rc14 & 11 & 5.2 \\
\hline Rc 28 & 20.1 & 10.2 \\
\hline Rc64 & 27.2 & 17.8 \\
\hline Rc 90 & 37.1 & 19.5 \\
\hline
\end{tabular}


We find that conservation in water gives the best result.

\section{4- COMPARATIVE STUDIES}

To classify the oversulfated cement obtained, a comparative study was carried out.
The comparative study was carried out on normal mortar with prismatic test tubes $4 \times 4 \times 16 \mathrm{~cm}^{3}$, we determined the resistance to traction by bending $\mathrm{Rt}$ and resistance to compression $\mathrm{Rc}$

Price

Either $\mathrm{x}$ the price of Oversulfated Cement $\mathrm{x}=0.65 \mathrm{P}-0.05 \mathrm{G}-0.15 \mathrm{C}-0.15 \mathrm{~L}$

$\mathrm{x}=(0.65 \times 160)-(0.05 \times 184)(0.15 \times 540)(0.15 \times 400)$

Table 7 : comparison of mechanical resistance on normal mortar and price.

\begin{tabular}{|c|c|c|c|c|c|c|c|c|c|c|c|}
\hline \multirow[t]{2}{*}{ Cement } & \multicolumn{5}{|c|}{ Rt (Mpa) } & \multicolumn{5}{|c|}{ Rc (Mpa) } & \multirow{2}{*}{$\begin{array}{c}\text { Price } \\
(\mathrm{Ar} / \mathrm{kg}))\end{array}$} \\
\hline & $7 \mathrm{j}$ & $14 j$ & $28 j$ & $64 j$ & $90 \mathrm{j}$ & $7 j$ & $14 \mathrm{j}$ & $28 j$ & $64 j$ & $90 \mathrm{j}$ & \\
\hline CP & - & 5 & 7.6 & 8.1 & 10.2 & - & 22.9 & 41.8 & 55.6 & 59.3 & 255 \\
\hline $\begin{array}{c}\text { Ciment } \\
\text { MANDA CPA } \\
42,5\end{array}$ & 6 & 6.8 & 7.2 & 7.5 & 8.1 & 30 & 36.1 & 47.8 & 49.5 & 50.3 & 540 \\
\hline
\end{tabular}

It is noted that natural pouzzolane-based cement can compete with conventional cement produced by Holcim at the mechanical characteristic level and at the price level. It can then be classified among the resistance class cements 42.5 .

\section{5- DISCUSSIONS}

This chapter allowed us to set the different parameters for the development of a cement based on natural pouzzolane consisting of a well-defined mixture of natural pouzzolane, gypsum, lime and conventional cement used in Madagascar.

The granulometry of all constituents is less than $80 \mu$ or at most equal to $80 \mu$. This choice is necessary because it is the granulometry adopted for all cements.

In terms of reactivity, the natural pouzzolane used is not very reactive, it required activation treatments, a thermal treatment of 2 hours at $500^{\circ} \mathrm{C}$ was the most effective. An increase in the temperature of the insulated bearing does not cause any increase, but on the contrary a slight decrease in reactivity, which may be due to a partial reorganization of the crystalline network of certain constituent of the pouzzolane.

By thermally treating a pouzzolane lime mixture, one generally records a decrease in mechanical resistance, the cooking of the mixture does not lead to the combination of lime with the acid constituents of the pouzzolane, it results in the formation of quick lime, which when wasting the mixture hydrates again. This rehydration has two major drawbacks: an increase in demand for waste water, and a strong release of heat. Both of these drawbacks eliminate the use of this kind of activation.

It seems that the simultaneous presence of gypsum and lime is necessary because lime corrects the composition of the pouzzolane and pure gypsum allow for the formation of calcium sulfoaluminate.
The best results are obtained with the composition $65 \%$ pouzzolane, $5 \%$ gypsum, $15 \%$ cement, $15 \%$ lime.

The optimal proportions of lime and cement may correspond: the amount that can be combined with the acidic constituents of the pouzzolane for lime, and the amount needed to form calcium sulfoaluminate during hydration of the cement.

Several studies have been carried out on the use of natural pouzzolane as building material. It has been used as an addition to reduce $\mathrm{CO}_{2}$ emissions and also to reduce the cost of production. The method used is that the natural pouzzolane incorporated into the mortars is exposed to an attack of 5\% sulphuric acid. The results show that natural pouzzolane improves the resistance of mortars to acid [4]. For our case, the activation of the pouzzolane was carried out by thermal activation, for them, the pouzzolane content in the mixture is $0,10,20$ and $30 \%$, for our case, the natural pouzzolane is not used as an addition but as a cement substitute, it is to say that the natural pouzzolane content used in the mixture is $65 \%$. We can then say that both methods can reduce greenhouse gas emissions and cost but our method has another advantage by using more natural pouzzolane than cement, another advantage is that our method does not use chemicals.

It is also observed in the results obtained that the thermal activation of the natural pouzzolane is at $500^{\circ} \mathrm{C}$, yet that of clinker is $1400^{\circ} \mathrm{C}$, so the energy demand is smaller if we use natural pouzzolane. As a result, greenhouse gas emissions are decreasing.

\section{6- CONCLUSION}

The objective of this work is to determine the behaviour of test tubes composed of mixtures of raw materials such as: gypsum, lime, natural pouzzolane, available and abundant resources in Madagascar. 
Before the experimental trials, we carried out bibliographical studies to acquire and especially to confirm from the experimental studies the different results of the technical literature. During our study, several parameters influence the behaviours of oversulfated cement test tubes, the most important of which are: the content of pouzzolane, and lime.

Experimental trials have shown us that:

- The activation temperature of the pouzzolane is $500^{\circ} \mathrm{C}$, with a cooking time of 2 hours;

- The mixture $65 \%$ pouzzolane - $15 \%$ cement - $15 \%$ lime - 5\% gypsum gives the best result

- The mechanical performance of oversulfated cement is observed mainly in the long term

- Withdrawal is low

The resulting oversulfated cement can be classified as a resistance class cement 42.5. Its production requires less energy than conventional cement, therefore emits less greenhouse gases.

Our study has allowed us to confirm that it is possible to produce a material based on locally available raw material such as pouzzolane, having characteristics that meet the requirements of the materials used in Madagascar.

\section{BIBLIOGRAPHY}

1. Ouedraogo, M. (2012) "Impact des changements climatiques sur les revenus agricoles au Burkina Faso ». JAEID 106(1).

2. Kamal Mohammedi et al., Congrès de Mécanique 23-26 (Avril 2013) Agadir (Maroc)

3. Projet SPECIMENS : "Contribution à la Réduction des Emissions de $\mathrm{CO}_{2}$ et à l'Amélioration des Performances Exergétiques des Cimenteries"

4. Segui, Pauline (2011) «Elaboration de liants hydrauliques routiers à base de pouzzolane naturelle ou de cendre volante de papeterie: thèse, Ecole doctorale MEGeP, laboratoire de recherche $L M D C$

5. L. Laoufi et al., (2016), "Evaluation de la durabilité de mortiers pouzzolaniques exposés à une attaque chimique » J. Mater. Environ. Sci. 7 (5) 1835-1845 ISSN : 2028-2508 CODEN: JMESC

\section{ABBREVIATIONS}

P : Pouzzolane ; L : lime ; C : Cement ; G : Gypsum 